\title{
"MAS ELE NUNCA ME BATEU": EFEITOS DE SENTIDO EM CIRCULAÇÃO NO NOME DE UMA PÁGINA DO INSTAGRAM
}

\author{
JENNIFER ALVARES ${ }^{1}$ \\ LARISSA M. CERVO ${ }^{2}$
}

\author{
Programa de Pós-Graduação em Letras \\ Universidade Federal de Santa Maria \\ Av. Roraima, 1000 - 97105-900 - Santa Maria - RS - Brasil \\ jealvares@outlook.com, laricervo@gmail.com
}

\begin{abstract}
Resumo. O cotidiano é constituído por um múltiplo de práticas que funcionam entre a repetição e a modificação em palavras/atitudes, fazendo ver que não há sujeito uno e individualizado discursivamente, vez que são posições inscritas em redes de filiações de sentidos, ressoando efeitos. $\mathrm{Na}$ sociedade brasileira circulam dizeres cristalizados na ordem de um já-dito que se apresentam como genéricos discursivos, significando por meio da relação necessária com a memória discursiva. Buscando refletir sobre um desses em relação à violência de gênero, selecionamos a página @ maselenuncamebateu para analisar como o deslize da nomeação inscreve um dizer em significações outras, na ordem da problematização do funcionamento discursivo outrora significante sobre violência(s).
\end{abstract}

Palavras-chave: Discurso; Memória; Gênero, Violência(s).

\begin{abstract}
Daily life consists in a multiple of practices that work between repetition and modification in words/attitudes, showing that there is no single and discursively individualized subject, cause they are positions inscribed in networks of affiliation of meanings, resonating effects. In Brazilian society, crystallized sayings circulate in the order of what has already been said, which are presented as discursive generics, meaning through the necessary relationship with the discursive memory. Seeking to reflect on one of these in relation to gender violence,we selected the page @maselenuncamebateu to analyze how the slip of the nomination inscribes a saying in other meanings, in the order of problematizing the formerly significant discursive functioning on violence(s)
\end{abstract}

Keywords: Speech; Memory; Gender, Violence(s).

\footnotetext{
${ }^{1}$ Discente do Mestrado em Letras da Universidade Federal de Santa Maria, eixo de estudos linguísticos, na linha de pesquisa Língua, Sujeito e História. Formada em Letras - Português e respectivas literaturas pela mesma instituição. Pesquisadora financiada pela CAPES.

${ }^{2}$ Docente do Departamento de Letras Vernáculas da Universidade Federal de Santa Maria e do Programa de Pós-Graduação em Letras. Orientadora da pesquisa.
} 


\section{INTRODUÇÃO}

O Brasil é constituído por uma pluralidade que vai para além de fatores largamente debatidos nos dias de hoje, tais como o racial e/ou classista tão somente; há um amplo espaço que faz com que em um mesmo momento o morador do sul esteja em uma temperatura próxima ao negativo, enquanto o morador da outra ponta extrema do país passe pelo calor de mais de 30 graus Celsius. Nesse espaço de muitas variáveis não só climáticas, há um múltiplo diversificado de práticas consideradas culturais e identitárias que, por vezes, são totalmente distintas. Compreendemos as práticas do(s) sujeito(s) e os sujeitos em si como muitos em suas posições e afetados por condições várias, o que leva a um ímpar de possibilidades para definir o que é ser brasileiro em um mesmo país. Ao passo que, nestas distinções também existem as semelhanças compartilhadas por um mesmo povo que nesta terra (se) significa. Quer dizer, ainda que identifiquemos o que nos diferencia um do outro pelo processo de identificação do "eu" (PÊCHEUX, 2014), ao mesmo tempo também compartilhamos de semelhanças que nos tornam brasileiros, sujeitos de uma mesma nação. Assim, reconhecendo que não há sujeito completamente "idêntico", acreditamos que há modos de aproximar diferenças na relação com suas semelhanças, compreendendo os genéricos discursivos, muitos nesse território de condições de produção variáveis, como um ponto similar aberto à análise que diz do sujeito e das condições de seu território, ecoando efeitos de sentido através da inscrição em uma memória, que pela prática teórica em que nos inscrevemos é designada como memória discursiva.

Quem não ouviu ou leu alguém dizer que "em briga de marido e mulher ninguém mete a colher"? Ou ainda, "que homem não chora"? Ou talvez que "mulher no volante, perigo constante!"? A lista é grande. "Senta como mocinha", "Já sabe cozinhar, pode casar", "Mulher e carro, quanto menos rodados, melhor", "Quem mandou sair com aquela roupa? Pediu...", "Mulher só é boa pilotando fogão", e seguindo assim a lista não terminaria em umas poucas linhas. Esses dizeres podem receber diversas denominações; há quem diga se tratar de ditos populares, há quem chame de jargões da cultura machista, aqui os tomamos teoricamente pela nomenclatura de genéricos discursivos, os quais se caracterizam por serem dizeres (re)produzidos socialmente ao longo do percurso histórico em condições variadas e possuindo semelhanças/recorrências ao mobilizar determinados sentidos e não outros. São fórmulas mais ou menos similares no que diz respeito à produção de sentidos, repassadas entre os sujeitos por um espaço temporal não determinado (isso não significa que seja a-histórico, tal como discutiremos mais à frente), sem um alguém a quem se possa imputar uma autoria (é da ordem do coletivo?), mas que estão inseridas em um processo parafrástico e corroborando para que o esquecimento da ordem da enunciação (PÊCHEUX, 2014, p. 161) funcione, ou seja, o léxico é uma escolha dos sujeitos e "o modo de dizer não é indiferente aos sentidos" (ORLANDI, 2015, p. 33).

Logo, vemos a problematização de tais dizeres e formulações, os genéricos discursivos, como campo fértil de reflexão e abertura aos questionamentos que desestabilizam a ordem da evidência, daquilo que é/está claro, ou melhor dizendo, que coloquem perguntas a uma materialidade linguístico-oral para além da opacidade que se faz visível aos sujeitos como "o" sentido, aquilo que só pode ser dito assim (ORLANDI, 2015, p. 32-3). 
De tal maneira, nossa proposta para este artigo objetiva ler discursivamente um destes genéricos, que encaixamos inicialmente como parte da formação discursiva (FD) a qual pertencem os exemplos acima mencionados, qual seja, a formação discursiva conhecida como machista e misógina, sobretudo aquela que diz respeito à legitimação da violência de gênero que acomete, na especificidade de nosso trabalho, as mulheres brasileiras. Não pretendemos fechar a formulação e circulação dos efeitos que ressoam em tais formulações como pertencentes à FD $x$ ou $y$, mas buscar compreender como tais genéricos produzem discursivamente significações semelhantes no tocante à violência contra a mulher, seja no deslegitimá-las e/ou colocá-las como ponto de reflexão e desestabilização. O que buscamos com uma tal leitura que questiona tais dizeres por meio dos sentidos que emanam pelos (e nos) sujeitos é buscar o fio do discurso em funcionamento nas formulações de uma FD dada. Especificando, como explica Pêcheux ao tratar do discurso como passível de estudo por sua materialidade linguística, entendemos que

[...] em termos tomados de empréstimo à lógica, pode-se dizer que a normalidade local que controla a produção de um tipo de discurso dado concerne não somente à natureza dos predicados que são atribuídos a um sujeito mas também às transformações que esses predicados sofrem no fio do discurso e que o conduzem a seu fim, nos dois sentidos da palavra (PÊCHEUX, 1993, p. 74, grifos do autor).

Então, selecionamos o perfil @maselenuncamebateu, encontrado na rede social Instagram, para a análise de como pelo deslocamento dos sentidos produzidos por esse genérico discursivo que circula, ainda, no Brasil, as administradoras e colaboradoras dos conteúdos publicados contribuem para a quebra do significante de tal fragmento e remetem às violências outras que não apenas a física como forma legitimada de romper a integridade da mulher, focando sobretudo no âmbito doméstico. Ou seja, em nosso gesto analítico trabalharemos com a própria nomeação do perfil na rede social bem como parte do material nele em circulação para refletir sobre como um dizer oriundo do imaginário de que violência decorre apenas das marcas físicas desliza e problematiza as formas outras de se violentar o sujeito-mulher.

\section{ENTRELAÇAMENTOS TEÓRICOS}

Nossa perspectiva de trabalho parte da teoria da análise de discurso francesa, ou pecheuxtiana. Nosso objeto teórico é o discurso, aquilo que o fundador da teoria denomina como "efeitos de sentido entre os pontos A e B" (PÊCHEUX, 1993), efeitos esses que têm como lugar material de sua realização a língua, a qual se relaciona e liga diretamente aos processos discursivos em constante funcionamento/transformação (PÊCHEUX, 1993, p. 172).

Não iremos trabalhar apenas com a textualidade exposta no perfil da rede social que recortamos, mas, sim, com aquilo que por meio da língua(gem) materializa e indica o acesso ao discursivo. É por intermédio de tal compreensão teórica que selecionamos a possibilidade de escolha para o que tomamos como objeto analítico, uma vez que "Para o analista de discurso a língua não será objeto de investigação primordial, mas um pressuposto fundamental para analisar a materialidade do discurso" (FERREIRA, 2003, p. 197). A nomeação da página é para nós parte do funcionamento do processo discursivo 
e, por isso mesmo, produz efeitos nos sujeitos que por ela são afetados e produzem significação acerca do nome e conteúdo veiculado no espaço da rede digital, e externamente a ele.

Empreendemos nosso gesto como prática de leitura que primeiro acesso tem à superfície linguística (o nome e o conteúdo das postagens), para que por meio dela procedamos à transformação em objeto discursivo através do procedimento da (de)superficialização teórico-analítica, anulando a ilusão de "o" sentido e, então, possamos trazer como o processo discursivo está significando por e para sujeitos (PÊCHEUX, 1993, p. 180-1). Esse é o nosso fazer analítico. Não articulamos uma leitura que fique na descrição do evidente, porque objetivamos interpretar/compreender como o sentido desse genérico, "mas ele nunca me bateu", significa aos sujeitos da/na rede. Estes/as, quando afetados por uma certa formação discursiva (FD) e em condições específicas podem reconhecer que a violência ocorre apenas quando se bate, agride, machuca o/a outro/a fisicamente. Porém, em outra condição dada e inscrição em outra FD dada passam a compreender que esse "mas" funciona como lugar de deslocamento, cujo olhar entende que a violência não precisa deixar marca(s) no corpo para que seja assim mesmo violência, afetando e subjugando quem por ela é vitimada.

A escolha de trabalho analítico com um perfil de rede social se deu por vermos como significativa de uma maneira outra a circulação discursiva neste espaço, que é específico por ser da ordem do digital, como aponta Dias (2018). É um discurso digital, como ela o define teoricamente, demarcando a especificidade de como os efeitos de sentido ali ressoam. Não desligado da produção linguística escrita em papel ou da oralização entre dois sujeitos frente a frente, por exemplo, mas contendo condições de produção que o tornam um discurso em funcionamento com suas características próprias, isto é, afetando e sendo afetado por e para sujeitos em condições dadas, que são as da rede tecnológica. Aliás, não só ligado às formas outras que fazem circular as discursividades, mas também, e sobretudo, parte fundamental da (re)formulação discursiva nos tempos atuais, porque instaura um processo discursivo que é determinado pelas condições da rede. É o que afirma Dias, dizendo:

O que significa pensar a tecnologia em sua condição de produção? Significa 'devolvê-la à história' ou 'considerá-la em sua historicidade' procurando compreender seus efeitos. Parece que temos invertido essa situação, ao considerar a história um produto da tecnologia e não a tecnologia um produto histórico. Tudo isso deriva do sentido de transparência da tecnologia. E dele o sentido do desaparecimento do sujeito mediante a máquina. Embora possamos afirmar que na máquina não há sujeito, é certo que sem sujeito não há máquina (DIAS, 2018, p. 44).

O uso da internet e das redes sociais é rotineiro a uma vasta parcela da sociedade brasileira, sobretudo com a expansão tecnológica produzida na última década. Assim, milhares de sujeitos acessam diariamente, ou quase isso, seus "perfis" nestes sites ou aplicativos. São sujeitos afetados pelo e afetando $o$ discurso digital, pois é por meio dos sujeitos que a formulação e a circulação são possibilitadas nesse universo tecnológico da/na rede. De certo modo, é em tal espaço que muitos sentidos tanto se reproduzem no processo parafrástico de circulação dos sentidos (PÊCHEUX; FUCHS, 1993, p. 169), sob a ilusão constitutiva de uma existência do livre-anonimato virtual onde se poderia "dizer 
tudo", quanto são postos à tona na problematização que busca deslocar certos préconstruídos (MARANDIN, 1993, p. 138-9) sob a ordem da evidência, entendendo que o ideológico também e sempre está constituindo tal espaço.

Percebemos o lugar do discurso digital como espaço em que o sujeito se sente com maior liberdade para sustentar/defender o seu dizer, naquilo que teoricamente identificamos como a posição-sujeito de autoria (ORLANDI, 2007, p. 79). Tal posicionamento demarcado, identificação sustentada na e sobre a materialidade da língua que circula nas redes, pode tanto ocorrer pelo uso do "eu" nomeado como "alguém no mundo", quanto pelo anonimato de uma "voz sem nome", sendo que o interdiscurso e a memória discursiva aí fazem com que os esquecimentos 2 e 1 (PÊCHEUX, 2014) estejam a todo o tempo permeando os sentidos que circulam e se (re)formulam. Pensaremos e colocaremos algumas questões sobre isso nas próximas páginas.

Pontuamos nos exemplares da introdução que os ditos reproduzidos derivam de uma FD machista, mas para que não se proceda a uma simplificação e fechamento da compreensão de como identificamos uma FD particularizada em relação às demais, retomamos as palavras de Orlandi, uma vez que,

No entanto, é preciso enfatizar que a formação discursiva não funciona como uma máquina lógica. Ao contrário, ela é uma unidade dividida, uma heterogeneidade em relação a si mesma. Há um deslocamento contínuo em suas fronteiras, em função das 'jogadas' da luta ideológica, dos confrontos político-sociais (ORLANDI, 2007, p. 109).

Por esse fato, por possuir fronteiras fluidas, é que o mesmo dizer pode significar diferentemente, pois não é exclusivamente pertencente a uma FD ou outra, mas atravessaas, passa por-entre elas. Não há fechamento, não há barreira estanque. Eis porque o "mas", conjunção adversativa segundo a gramática da língua portuguesa, pode ser tomado em dois pontos extremos ressoando sentidos (e não só) como elencamos anteriormente, "Isso equivale a afirmar que as palavras, expressões, proposições etc., recebem seu sentido da formação discursiva na qual são produzidas" (PÊCHEUX, 2014, p. 147).

Em nossas pesquisas articulamos a teoria que é nosso ancoradouro com outro campo que para nós se faz necessário a fim de compreender o como e o porquê há perpetuação da recorrência de violência(s) contra a mulher, ainda que muito se questione acerca contemporaneamente, que é o dos estudos de/sobre gênero e feminismo. Assim, acreditamos na urgência de tal articulação como uma dentre as possibilidades de colocar questões e simular possíveis respostas que abarquem a violência de gênero como prática do/no ideológico misógino e patriarcal brasileiro. Por violência de gênero não compreendemos apenas aquela que subjuga a mulher, cis ou trans, hétero ou homo, mas toda e qualquer forma de coerção e agressão que se dê pautada pelo desprezo à identidade de gênero com a qual a pessoa agressora não se identifica.

Quer dizer, um homem também é vítima da violência de gênero quando chamado de "marica" por ser considerado sentimental além do que o masculino "permite". Um gay sofre violência de gênero por ser considerado "afeminado demais". Uma trans é espancada e morta cotidianamente por "não ser mulher de verdade". Todos estes préconstruídos funcionam socialmente como genéricos discursivos que, pautados em uma binariedade de gênero, hierarquizam o masculino em oposição ao feminino, com graus 
de violências que perpassam da psicológica à física. Ainda, vale trazer à reflexão um apontamento que Heleieth Saffioti faz de crítica à simplificação do que se compreende pela conceituação do termo gênero, em que diz que

Gênero é um conceito por demais palatável, porque é excessivamente geral, a-histórico, apolítico e pretensamente neutro. Exatamente em função de sua generalidade excessiva, apresenta grande grau de extensão, mas baixo nível de compreensão (SAFFIOTI, 2011 [2004], p. 138-9).

Por meio das relações que empreendemos entre $\mathrm{AD}$ e estudos de gênero não interpretamos o conceito tal qual ela dispõe nesse trecho, isso porque, compreendemos ser pelo apagamento do funcionamento ideológico constituinte dos discursos e dos sujeitos que a opacidade do significado de gênero na sociedade brasileira se torna a parte estruturante, autorizando a binariedade gendrada como a única (ou melhor) forma de existência aceita dos sujeitos.

Assim, não é a-histórico porque se constitui em determinadas condições que cerceiam significações umas e não outras; não é apolítico porque a própria palavra retirada da ordem da evidência delineia como sua compreensão se dá em um processo todo-complexo com dominante (PÊCHEUX, 2014, p. 148), e não é neutro justamente por ser o lugar de questionamento do embate que se coloca entre o que é do biológico ("natural") e do social ("cultural") (BUTLER, 2008; SCOTT, 1995). De tal maneira, falar de gênero como parte do funcionamento discursivo de violência contra a mulher busca romper com a opacidade discursiva que entende a física como a "verdadeira" violência e/ou que não existem distinções entre aquela que acomete a alguém pela especificidade de gênero, (des)significando aquilo caracterizador das agressões violentas por motivação de gênero.

O digital é um dos espaços onde a problematização acerca da violência de gênero vem ganhando abrangência e atingindo sujeitos muitos, que tanto concordam com a desestabilização de uma formação discursiva que inscreve dizeres machistas e patriarcais como os "corretos", quanto refutam e contrapõem tal problematização, tratando-a por "vitimização de feminista". Se trazemos tantas aspas é porque são elas que mostram o cristalizado abordado em AAD-69 pelo nome de discursos-tipo, espaço no qual diferentes tipos de memória são mobilizados (PÊCHEUX; LÉON; BONAFFOUS; MARANDIN, 1993, p. 273), e tratam do funcionamento próprio aos genéricos discursivos, os quais precisam de um destaque para entendê-los como não natural/neutro/claro/evidente. Em seus trabalhos sobre o digital como lugar de discursivização com efeitos específicos, Dias (2009) designa que a instauração de modos de escrita outros advindos deste espaço afetam a relação que o sujeito tem com a língua(gem), seus conhecimentos sobre ela, logo, suas relações imaginárias e sociais produzidas por meio do ato de teclar e de digitar (DIAS, 2009, p. 12-5).

Em uma escrita padrão a ilusória atenção à forma do conteúdo, enquanto no digitar/teclar a liberdade de dizer como se quer na velocidade da internet enquanto espaço sem regras formalizadas. Assim é que o internetês passa a ser por alguns considerado uma língua outra, a qual o sujeito acessa nesse e somente nesse lugar da rede, do perfil social, das mídias digitais de envio de mensagens instantâneas que prezam pela aceleração da compreensão e do dizer mais que à forma como se diz. Contudo, pelo viés discursivo 
compreendemos não se tratar de uma nova e/ou outra língua, mas de maneiras outras de identificação do sujeito com o simbólico (CERVO, 2012, p. 71), as quais afetam sua relação tanto social quanto imaginária com o outro e consigo através do que Orlandi (2015, p. 37-40) designa como o mecanismo das formações imaginárias, em que as relações de força, de sentidos e a antecipação operam no modo como o sujeito faz uso da linguagem no espaço da internet, que apresenta determinadas variações do espaço físico/empírico. Daí a ascensão de uma ilusão constitutiva do lugar da rede como mais amplo à liberdade de expressão e circulação, pois o sujeito acredita ter maiores possibilidades de sustentar suas palavras sem o receio da coerção por parte de outrem, seja ela física ou não. Ou seja, de acordo com Romão, "A liberdade apresenta-se como a moeda de troca no campo da virtualidade multidimensional, já que sempre existe a possibilidade de deslocar-se, mover-se com grande desenvoltura e velocidade" (ROMÃO, 2004, p. 73). Logo, por pouco que percorramos a timeline de uma rede como o Instagram, percebemos o acúmulo/excesso/múltiplo de conteúdos à disposição, uma interposição do jogo das formações imaginárias a todo instante, (re)significando.

As páginas/perfis em redes sociais tais como Instagram, Facebook, Twitter etc., que se definem e caracterizam pelo questionamento do status quo social procedem à inserção de discussões que não são oriundas do digital, mas de lutas marcadas por suas próprias condições de produção como, por exemplo, o feminismo, o qual possui caracterizações de um movimento social pela igualdade de gênero muito anteriormente da criação de um sistema online de reivindicações (PINTO, 2003). Eis o que a autora Cristiane Dias nomeia como a digitalização do mundo, entendendo-a como

[...] práticas de linguagem que tendem à metaforização das relações sociais e das práticas dos sujeitos que, por meio do acesso deslocam o campo da 'luta' para uma inscrição na forma digital. Em outros termos, a digitalização do mundo é um processo de historicização dos sentidos que desloca o modo de significação, produzindo uma forma material outra, porque inscreve o dizer, o fazer, as práticas dos sujeitos, em outras condições de produção, afetada por outras instituições, como as corporações do tipo Google ou Microsoft, garantindo o funcionamento da máquina ideológica por meio das relações de poder e de produçãoreprodução do trabalho (DIAS, 2016, p. 10-11).

Desta forma, não há como comparar a prática dos sujeitos da rede social @ maselenuncamebateu como igual às práticas feministas que mulheres empreenderam durante o período sufragista, por exemplo, ou à prática teórica acerca dos movimentos feministas e estudos de gênero que se (re)fazem na Academia. Como as condições são diversas, não há igualdade entre estes pontos, mas semelhanças inscrevendo os sujeitos e os discursos por eles produzidos em redes de filiação (ORLANDI, 2012, p. 10) que buscam deslocar aquela ordem naturalizada de que é única e exclusivamente pelo/no corpo que a violência existe. Buscamos acessar as particularidades e semelhanças pela leitura e gesto interpretativo de nossa prática teórica, considerando o discurso como objeto teórico-analítico, os estudos sobre gênero e feminismo como uma relação pertinente com a $\mathrm{AD}$, e o digital como espaço específico de formulação sustentado na circulação de um aqui e agora (DIAS, 2018, p. 33-4) que busca ampliar a afetação dos sujeitos sobre a violência doméstica contra a mulher, na busca de fazê-los questionar significações e dizeres cristalizados na memória do sócio-ideológico-historicamente posto. 


\section{AS CONDIÇÕES DE PRODUÇÃO E O NOME DE USUÁRIO NO FUNCIONAMENTO DISCURSIVO DA @MASELENUNCAMEBATEU: HISTÓRIA, MEMÓRIA E O RESSOAR DE SENTIDOS}

As redes sociais são parte do cotidiano de muitos sujeitos em todo o mundo, desempenhando diversas funções. Tendo início com os "perfis pessoais", onde sujeitos possuíam sites/blogs para falar de si ao outro, de assuntos os quais tinham interesses, de informações acerca da sociedade e de reflexões em voga a cada época. A sociedade experienciou um múltiplo dessas propostas, sobretudo após a ascensão do uso da internet no Brasil, que cresceu e continua a conter cada vez mais adeptos da virada do século até o presente momento. Atualmente tudo (ou quase) pode ser encontrado, apresentado, questionado e viralizado nesse espaço específico do digital. É parte da memória metálica que Orlandi (2015) define como aquela do acúmulo, do excesso, do múltiplo, que significa e faz específica o que Dias denominou particularmente como memória do/no digital (DIAS, 2018, p. 161). A segunda é diferente da primeira, mas não está desligada em todo dela; porque desloca a idealização maquinária de completude do arquivo como passível de acesso completo ao inscrever-se no funcionamento discursivo do digital, "que escapa à essa re-atualização, instalando-se na memória discursiva, pelo trabalho do interdiscurso, considerando o acontecimento do digital" (DIAS, 2018, p. 161). É, portanto, parte estruturante do interdiscurso tanto quanto o que acontece fora da rede, pois faz com que os genéricos discursivos que produzem efeitos no mundo empírico também estejam presentes na significação dos perfis sociais. E em sendo discurso funcionando, que acesso tem à memória discursiva, inscreve o teclar/digitar em redes de filiações de sentido, ou seja, o que ali circula também faz parte das FDs, constituindo sujeitos e sentidos.

O Instagram é, atualmente, uma dentre as centenas de redes sociais existentes e que mais possuem acesso em todo o mundo, sendo que no Brasil a porcentagem de usuários ultrapassa a média mundial ${ }^{3}$. Criado em 2010 por dois jovens, passou a integrar o grupo de redes pertencentes à gigante Facebook, também popular, do CEO Mark Zuckerberg. A proposta inicial de que os sujeitos fizessem a criação de seus perfis para postagens de fotos no estilo Polaroid foi sendo modificada e, cada vez mais, funções são adicionadas à plataforma que, além de ser um aplicativo para os sistemas operacionais de celulares como no início, conta agora com a possibilidade de uso pelos aparelhos de computador/notebook. Tal rede afeta e é afetada pelo sistema capitalista, pois se dá em condições que não a desligam do funcionamento ideológico, ou seja, há ali não só os perfis pessoais dos sujeitos, mas perfis e páginas que buscam o aumento de capital, seja pelas vendas, publicidade, entre outras muitas formas de monetizar o perfil/página. Também, há diversos perfis com objetivos pedagógicos de áreas as mais variadas, nas quais o recorte que fizemos está inserido, que muitas vezes iniciam com o objetivo de ampliar o conhecimento sobre determinada pauta/assunto e em decorrência da estrutura social em que estão inseridos deslizam para a produção econômica também, entram no "jogo" do vender(-se) nas redes sociais, muitas vezes sequer percebida pelos usuários/seguidores. É um ponto que entendemos como aberto à reflexão, pois

Os desdobramentos desse período [a era do século 21] fazem parte do mundo que se produziu discursivamente como uma "utopia

\footnotetext{
${ }^{3}$ Informações sobre a rede podem ser acessadas em diversos sites, indicamos aqui o TechTudo, Wikipédia, Canaltech, Tecmundo e Oficina da Net àqueles que tiverem interesse.
} 
tecnológica", apagando o político e o ideológico do processo de significação do desenvolvimento da tecnologia como dispositivo de controle. O que não é próprio da tecnologia, mas do desenvolvimento de uma sociedade capitalista onde as relações de poder se pautam na produção de dispositivos de controle sobre o outro e sobre os desejos do outro" (DIAS, 2018, p. 26).

\section{Recorte 1: Página inicial}

A página @ maselenuncamebateu 4 é uma dentre as milhares inseridas na memória

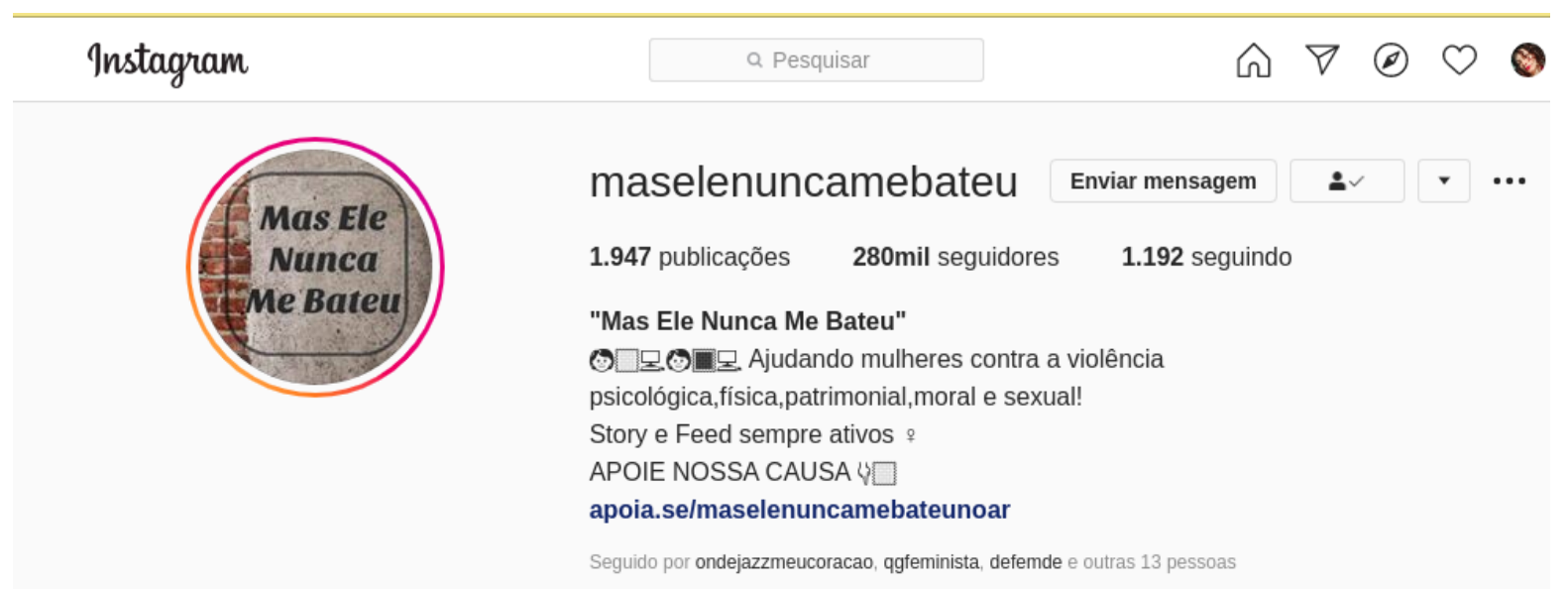

digital-discursiva dessa rede social, administrada por mulheres e que busca tratar de questionamentos e reflexões acerca da violência de gênero, com o foco especial na violência doméstica contra mulheres. Sua nomeação não é aleatória, trata-se da reprodução de um já-dito cristalizado na ordem do funcionamento discursivo de uma FD que por décadas foi repetida e materializada no imaginário brasileiro sobre violência, a qual legitimava e reconhecia apenas a existência daquela violência que deixava marcas visíveis nos corpos. E esse nome só funciona para (des)estabilizar um já-dito porque há nele o funcionamento do processo discursivo permeado pelo interdiscurso, uma vez que

A condição essencial da produção e interpretação de uma sequência não é passível de inscrição na esfera individual do sujeito psicológico: ela reside de fato na existência de um corpo sócio-histórico de traços discursivos que constitui o espaço de memória da sequência (PÊCHEUX, 2014, p. 145).

Em nossos recortes trazemos capturas de tela feitas no dia 20/08/2020, as quais primeiro mostram a parte inicial que pode ser visualizada logo ao acessar a página e, em seguida, por meio do acesso aos destaques ${ }^{5}$, dizem do objetivo a que se propõem as administradoras. No recorte 1 tem-se acesso aos dados iniciais que compõem tanto páginas públicas quanto perfis pessoais desta rede social. Ali, podemos ver qual o nome de usuário, nesse caso identificado pelo "maselenuncamebateu", o número total de publicações, de seguidores e de contas que o perfil está seguindo. Também, temos acesso

\footnotetext{
${ }^{4} \mathrm{O}$ acesso ao perfil pode ser feito através do link: https://www.instagram.com/maselenuncamebateu/. A página é de acesso público.

${ }^{5}$ Função específica do Instagram que permite a fixação atemporal de storys, publicações de duração originalmente datada em apenas 24 horas, mas que tornada destaque passa a ser fixa no perfil e distribuída logo acima das postagens feitas na linha do tempo.
} 
à descrição da página, ou seja, o que o seguidor (ou não) poderá encontrar de conteúdo ao acessá-la.

Compreendemos, na vertente pecheuxtiana, essa parte inicial como constituinte daquilo que funciona parafrasticamente a uma reprodução da vida social fora do digital, em que os sentidos sobre as identidades - quem sou eu, quem é você, quem somos nós estão a todo o tempo formulando-circulando pelo efeito que emana tanto da posição de autoria (o perfil pessoal ou página que se autodescreve no pequeno espaço desta seção inicial) quanto daquele que tem contato com essa descrição, o(s) efeito(s)-leitor (ORLANDI, 2012, p. 64), gerando um reconhecimento e/ou embate com o que ali está sendo veiculado, na luta de classes/identidades. (Re)produção discursiva dentro e fora das redes. Afinal, todas as relações são de "Contradição, reprodução, transformação, memória, esquecimento, o mesmo e o diferente, [e] jogam todo o tempo na produção de um discurso, ou de uma leitura" (ORLANDI, 2007, p. 110). Não seria diferente com a apresentação de um perfil público/privado no Instagram. A descrição é parte da identificação necessária do sujeito como "eu", autônomo, individual, identitário; só se pode dizer quem se é a partir do momento em que se reconhece nesse lugar que está significando(-nos) por meio de uma materialidade linguística, por meio de uma descrição, ao dizer "eu sou x", ou "eu gosto de x", ou "eu faço x", próprio à figura da interpelaçãoidentificação trazida em Semântica e Discurso (2014), entendendo que

essa identificação, fundadora da unidade (imaginária) do sujeito, apoiase no fato de que os elementos do interdiscurso [...] que constituem, no discurso do sujeito, os traços daquilo que o determina, são reinscritos no discurso do próprio sujeito (PÊCHEUX, 2014, p. 150, grifos do autor).

É pela identificação/descrição que os perfis se particularizam, diferenciam-se dos demais, resguardam o seu lugar próprio em relação aos outros. Imaginariamente, é claro, na ilusão da subjetividade que constitui a todo sujeito, e da evidência que permeia todo discurso. De tal maneira, a @maselenuncamebateu entra no jogo da antecipação, procurando atrair o público, seu público, por meio da elucidação do papel ao qual a página se propõe e o que ali é postado, tanto na imagem de perfil quanto nas palavras que seleciona para descrever(-se), de modo que "Esta antecipação do que o outro vai pensar é constitutiva de todo discurso" (ORLANDI, 1998, p. 76).

Podemos notar que o número de seguidores - aqueles que acompanham diretamente todas as postagens veiculadas - é expressivo se compararmos com os dados gerais de páginas ativas nessa rede social, mas, ainda assim, conta com um acúmulo que está muito abaixo de blogueiras/os, artistas midiáticos e cantoras/es, por exemplo. As redes sociais são o lugar do acúmulo, do excesso, do "quanto mais, melhor", mas melhor para quê(m)? 280 mil indivíduos seguindo é um número quase imperceptível se compararmos às estatísticas de usuários da rede, se estabelecermos uma interrelação com outros tipos de conteúdos e pessoas populares nesse espaço específico do digital. Não tencionamos adentrar dados numéricos nesta discussão, mas possibilitar ao leitor pensar não só no próprio uso das redes sociais, como também do conteúdo que ela circula/vende como o mais desejável, atraente, palatável (sim, na dubiedade significativa do termo) que está ligado à luta de classes (re)pensada pela discursividade em Pêcheux. 
Diante disso, podemos fazer uma relação/problematização com a memória discursiva que advém por intermédio do nome e é problematizada nos conteúdos ali dispostos? Há que se perceber no funcionamento da ordem do cristalizado e do esquecimento enunciativo nesse espaço aquilo que veiculado pode ou não ter a adesão dos sujeitos, já que se constituem em forma-sujeito livre e determinada (ORLANDI, 2007, p. 105). Quer dizer, sendo um discurso em funcionamento em condições dadas, mobilizando um todo complexo com dominante (PÊCHEUX, 2014, p. 148-9) que faz ecoar sentidos uns e não outros, ainda que a página e o que ela pretende significar da/na violência de gênero contra mulheres seja discussão em voga na atualidade, não escapa à memória discursiva que constitui a condição de produção da(s) ideologia(s) dominante(s) em solo brasileiro, qual seja, a machista/misógina/patriarcal, sendo por isso inferior em números "relevantes" no digital. Portanto, retomamos uma vez mais Michel Pêcheux ao afirmar que "Sabemos que toda prática discursiva está inscrita no complexo contraditóriodesigual-sobredeterminado das formações discursivas que caracteriza a instância ideológica em condições históricas dadas" (PÊCHEUX, 2014, p. 197). Não seria diferente com esse perfil aqui analisado.

Mas, seguindo ou não (a página e o conteúdo ali discutido), no deparar-se com a descrição e o nome os sujeitos, sejam identificados e inscritos em FDs as mais diversas, já são levados ao lugar do incômodo, do reflexivo, do problematizado como terreno aberto. Isso porque o dito e o não-dito ali produzem seus efeitos por meio da mobilização que se sustenta no interdiscurso, entendendo que "O interdiscurso disponibiliza dizeres que afetam o modo como o sujeito significa em uma situação discursiva dada" (ORLANDI, 2015, p. 19). Mesmo que refute tudo o que ali estiver disposto, o sujeito é instado a interpretar, discurso é sempre efeito que se realiza por intermédio da interpretação, assim, é possível afirmar que "No funcionamento da linguagem, como veremos, o sujeito é constituído por gestos de interpretação que concernem sua posição. O sujeito é a interpretação" (ORLANDI, 2012, p. 22, grifos da autora). Se os sujeitos se inscrevem na formação discursiva em que está inscrita a significação dada pelas administradoras ao nome da página e se identificam com a formulação-circulação discursiva que ali têm lugar e mobilizam a memória no inter/intradiscurso, então, há efeitos de sentido uns; se não há inscrição e nem identificação com o deslocamento que se propõe essa adversativa "mas", efeitos de sentido outros. Esse é o interpretar próprio aos sujeitos do/no discurso.

O duplo destaque do nome na primeira linha da descrição da página inicial, pelo negrito e pelas aspas, faz com que nessa escrita/digitação a relação significante que vem em seguida receba atenção, quando da visibilização das violências outras que ali serão abordadas, quais sejam, "Ajudando mulheres contra a violência psicológica, física, patrimonial, moral e sexual!”. Isso, posto em necessária ligação, produz, acreditamos, o efeito metafórico promovido pela conjunção adversativa "mas", a qual se recorre como ponto nodal de reflexão sobre as formas várias de agressão existentes e registradas juridicamente através da Lei Maria da Penha, lei $11.304 / 06^{6}$. Tal efeito, "Este deslizamento, a metáfora, própria da ordem simbólica, é o lugar da interpretação, da ideologia, da historicidade" (ORLANDI, 2012, p. 24). É o deslize que constitui ideologicamente a significação de um termo a/e outro pela substituição. Trazendo Pêcheux, "Chamaremos efeito-metafórico o fenômeno semântico produzido por uma

\footnotetext{
${ }^{6}$ Disponível para consulta em: http://www.planalto.gov.br/ccivil_03/ato2004-2006/2006/lei/111340.htm. Acesso em: 07/09/2020.
} 
substituição contextual para lembrar que esse 'deslizamento' de sentido entre x e y é constitutivo do sentido designado por x e y” (PÊCHEUX, 1993, p. 96).

Em nosso campo teórico a metáfora, o efeito metafórico, é designada pela troca/substituição de termos simbólicos que constituem o sentido da formulação inicial A à formulação final $\mathrm{B}$, que podem chegar a parecer totalmente desconectadas pela não semelhança de termos linguísticos resultantes desse deslizamento. Contudo, o efeito metafórico em nosso objeto analítico não se dá pela troca de palavras que modifica o ressoar dos sentidos, mas pelo próprio deslocamento que uma mesma formulação linguística vai provocar no processo discursivo em pleno funcionamento. Ainda que nada do genérico discursivo "mas ele nunca me bateu" seja modificado simbolicamente, os sentidos passam a gerar efeitos distintos, senão completamente opostos. Isso só é possível uma vez que

De fato, o sentido existe exclusivamente nas relações de metáfora (realizadas em efeito de substituição, paráfrases, formações de sinônimos), das quais certa formação discursiva vem a ser historicamente o lugar mais ou menos provisório: as palavras, expressões e proposições recebem seus sentidos da formação discursiva à qual pertencem. Simultaneamente, a transparência do sentido que se constitui em uma formação discursiva mascara a dependência desta última em relação ao interdiscurso. Na verdade, a metáfora, constitutiva do sentido, é sempre determinada pelo interdiscurso, isto é, por uma região do interdiscurso (PÊCHEUX, 2014, p. 240).

Exemplifiquemos: O sujeito ameaça, xinga, humilha, despreza a companheira, mas, por nunca tê-la agredido fisicamente, ela não pode sequer cogitar que sofra qualquer tipo de violência, afinal, aprendeu pelo histórico-social que isso só ocorre se ela apanha. Ele abusou psicologicamente, mas nunca bateu; ele a violou moralmente, mas nunca bateu; ele a feriu patrimonialmente, mas nunca bateu; ele a coagiu sexualmente, mas nunca bateu. É na nomeação, pelo deslize metafórico de uma conjunção adversativa inscrita em uma memória discursiva acerca de violência como somente física, que tem lugar a problematização de violações múltiplas que acometem diariamente o sujeitomulher sem que sejam evidenciadas, pois são opacas (ORLANDI, 2017, p. 151), tidas como da ordem do comum, cotidiano. A conjunção é a mesma, porém, pela inscrição em formações discursivas distintas, recebe significação e produz sentidos adversos. Os sujeitos ao se identificarem ou não com tal deslize são afetados de formas diferentes. $\mathrm{O}$ efeito metafórico é significativo porque os efeitos discursivos deslizam, irrompem e caracterizam a inscrição em outra filiação. 
Recorte 2: Destaque "Sobre nós!"

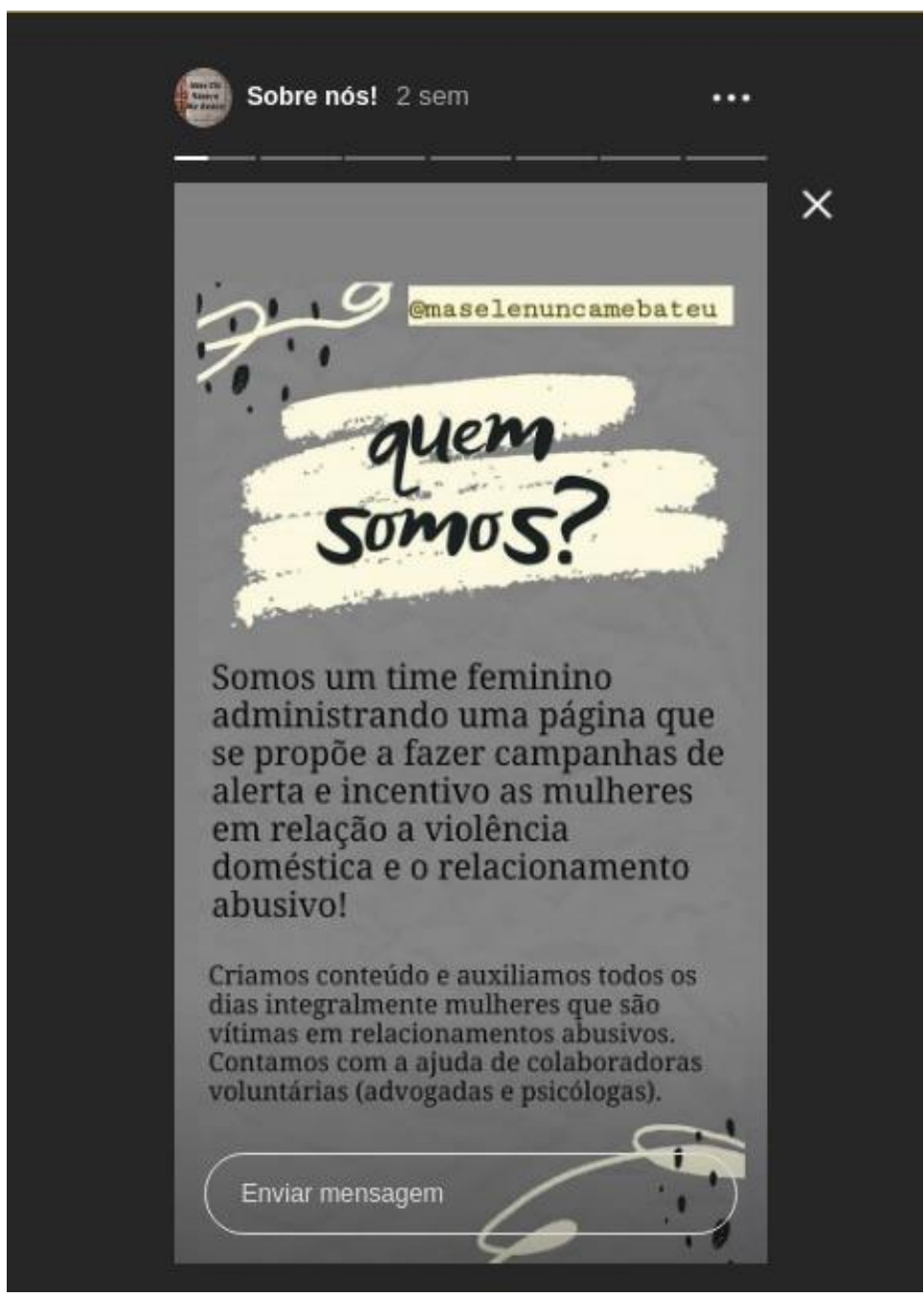

Recorte 3: Aba 1 da seção Destaques

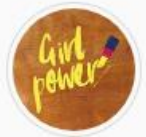

Empreend...

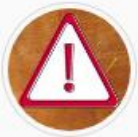

APOIE!



Sobre nós!

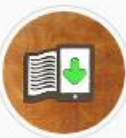

E-book

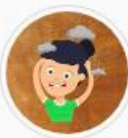

É abusivo??

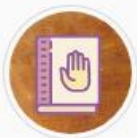

Manual do...

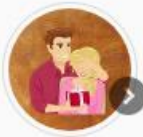

Hoovering

Recorte 4: Aba 2 da seção Destaques

(5)

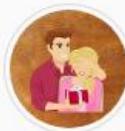

Hoovering

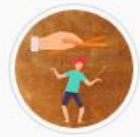

Gaslighting

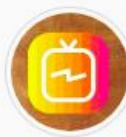

1 série!

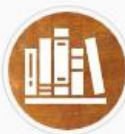

Dicas

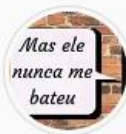

Livro

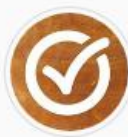

Consentir

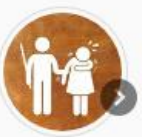

Estupro M... 


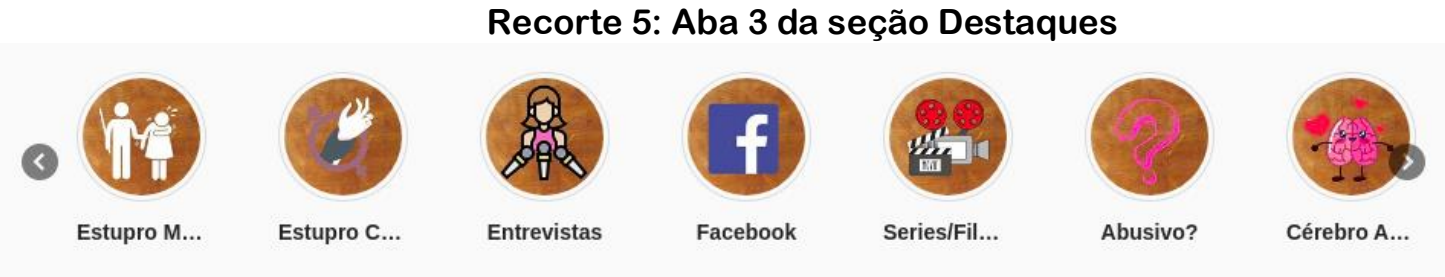

Já nos recortes seguintes, por meio da seção de destaques (Recortes 3, 4 e 5) e do destaque "Sobre nós!" (Recorte 2), há a didatização que as administradoras promovem como retomada do objetivo demarcado pela escrita/digitalização na descrição que identifica a página e da própria (re)significação que propõem com o uso do genérico discursivo que dá nome ao perfil. De tal modo, a conexão entre os recortes pode ser compreendida como parte do discurso dessa FD que desloca sentidos antes dominantes e da ordem da evidência, a fim de elucidar à população do "território da rede" como existem violências múltiplas acometendo o gênero mulher, que historicamente foram apagadas pelo funcionamento próprio da ideologia, acobertadas pelos esquecimentos que constituem discurso e sujeito, compreendendo que "O termo 'esquecimento' não está designando aqui a perda de alguma coisa que se tenha um dia sabido, como quando se fala de 'perda de memória', mas o acobertamento da causa do sujeito no próprio interior de seu efeito" (PÊCHEUX, 2014, p. 150). Funcionamento discursivo de uma FD machista/misógina/patriarcal que rebateu os questionamentos imputados tão só à violência física, vista por muitos como o único ponto passível de reflexão por muitas décadas, até a instauração da lei 11.304 em 2006.

Os estudos acerca da violência contra a mulher decorrem de décadas anteriores à promulgação da primeira lei nacional totalmente voltada para esse âmbito, sendo o período de 1975 a 1985 popularmente conhecido como "a década da mulher", em que diversos tipos de mobilização vieram à tona para problematizar um cotidiano de opressãoresistência, sendo significativa a instalação da primeira delegacia especializada no atendimento à mulher, em São Paulo, como conquista de uma luta coletiva (SANTOS, 2008). Assim, essas postagens dos destaques, que originalmente eram datadas para circularem por apenas 24 horas, em formato de storys, ao serem fixadas atemporalmente logo ao início da página acabam mobilizando sentidos outros que não estariam ali se estivessem inscritas tão somente na efemeridade de uma postagem que dura um único dia, uma vez que a todo instante todo e qualquer usuário do Instagram que acesse a página poderá ter conhecimento de tal material, de modo a inscrever-se ou não no efeito de sentidos que aquela didatização propõe.

Em “Sobre nós!", essas sujeito-autoras se definem a si como um "time feminino", mas o que da memória discursiva ressoa na significação do termo feminino que elas ali selecionam como marca identificadora de si e da página? Acreditamos, em decorrência dos estudos que vimos desenvolvendo nos últimos tempos, que a escolha lexical não é aleatória e acaba por mobilizar uns sentidos e não outros, de tal forma que o feminino usado por elas para definir(-se) traz um interdiscursivo acerca do que seja ou não o "papel natural de mulher na sociedade" (SAFFIOTI, 2004, p. 77), quer dizer, da biologização de que há coisas que são femininas e coisas que não são femininas. Se trata daquilo que é do real do discurso, da língua e da história, com o qual o sujeito se depara, não resiste, pois sempre-já “'[...] 'há real', isto é, pontos de impossível, determinando aquilo que não pode não ser 'assim', (o real é o impossível... que seja de outro modo)" (PÊCHEUX, 2015, p. 
29). O sujeito é sujeito porque é interpelado ideologicamente, então, ainda que elas busquem questionar o status quo da ideologia dominante, em pleno funcionamento pela materialização que o discurso toma da/na sociedade, não se desvencilham em todo dela, seguem sendo afetadas e deslizam, porque o real funciona nelas e por elas para que o discurso tenha significação.

Portanto, compreendemos o uso de "feminino" na sequência discursiva do recorte 2 como uma autodefinição que ressoa diferentemente do uso categórico de gênero, tal qual se elas tivessem definido a si como um grupo de mulheres, por exemplo. Ou ainda, por que não utilizar "time feminista"? Afinal, o trabalho empreendido por estas colaboradoras que produzem os conteúdos ali dispostos é inscrito em uma filiação, digamos, feminista, pois busca desestabilizar formulações e afirmações imperantes durante longo período de uma sociedade calcada em uma política do patriarcado. Assim é que a escolha empreendida deixa à tona a maneira pela qual o intradiscurso está em relação constante e direta com o interdiscurso, entendendo que o primeiro é o "fio do discurso" do sujeito, o qual carrega o próprio efeito do interdiscurso como se fosse exterioridade (PÊCHEUX, 2014, p. 154). É escolha que funciona discursivamente porque os esquecimentos estão ali encobrindo-a como se fosse evidente, como se não houvesse outro modo de dizer aquele dito. $O$ ponto principal a se refletir com essa identificação do "eu sou" no recorte 2 exposto, no destaque "Sobre nós", é de que algo falha, pois

Quando, no processo de afirmação do movimento feminista, o gênero se dissociou do sexo para afirmar o caráter cultural do significado atribuído a homens e mulheres nas sociedades, reforçou a desbiologização e a desnaturalização na constituição do sujeito 'mulheres'. (MARTINS, 2015, p. 241).

Retomando a citação de Saffioti (2004) que dispusemos no início desse texto queremos trazer o ponto de reflexão de, mesmo não concordando com a definição que a autora postula negativamente à categoria de gênero, ser preciso reconhecer o trabalho do ideológico no sujeito se dando na contradição "[...] constitutiva dos processos de produção de sentido e do sujeito" (ZOPPI-FONTANA, 2017, p. 64). Gênero por vezes surge como um conceito vazio, sem aprofundamento reflexivo. É preciso ir a fundo na compreensão de uma categoria que faz refletir o modo pelo qual as diferenças e violências decorrem de uma construção que é social, materializada na língua e na história dos discursos e sujeitos. Ou seja, mesmo ao identificar-se como sujeito/a problematizador/a da questão que envolve a violência de gênero em suas múltiplas facetas, elas recaem na opacidade da linguagem e trocam/misturam as categorias de sexo e gênero como se fossem o mesmo.

Queremos dizer, ainda que as administradoras desta página se inscrevam em uma FD que postula problemáticas ao funcionamento discursivo da ideologia machista que a todo tempo viola, agride e mata sujeitos enquadrados no gênero mulher, ao nomearem-se como um "time feminino" acabam recorrendo na ordem necessária de que o esquecimento número 2 (ORLANDI, 2015, p. 33) as afete e determine sua escolha do léxico. Logo, aí há a presença do esquecimento número 1, estruturante, o esquecimento ideológico, onde "[...] os sentidos apenas se representam como originando-se em nós: eles são determinados pela maneira como nos inscrevemos na língua e na história e é por isso que significam e não pela nossa vontade" (ORLANDI, 2015, p. 33-4). Uma vez mais, é o 
funcionamento do interdiscurso no intradiscurso pela FD, não há como apagar o histórico da/na língua.

Tal como está posto na descrição inicial da página, na captura de tela do destaque "Sobre nós!" as autoras descrevem o objetivo de trazer à tona a problematização e reflexão sobre formas outras de violências. Vale destacar, há algo novo, não é só sobre o violento, mas também acerca do relacionamento abusivo. A nomenclatura que surge de pautas do movimento feminista demarca o lugar que o deslocamento do "mas" no nome da página vem a defender, qual seja, o da relação abusiva, onde a violência física é um dos últimos e menores casos em dados estatísticos constatados, pois as outras formas de cercear a liberdade e autonomia da mulher na relação estão em pleno e constante funcionamento sem que grande parcela delas perceba. Portanto, o papel que estas mulheres se propõem no didatizar e refletir sobre toda e qualquer forma de violência, seja física ou não, vem a contribuir social e deslizar de uma FD à outra através do "mas" que se torna simbólico, emanando sentidos em tudo o que é publicado nesta página.

Por elencar dois conceitos que elucidam a apropriação de conhecimentos delas sobre o campo dos estudos de gênero, violência e feminismo, em uma mesma frase há mobilização de sentidos sobre estarem ligados. Ou seja, geram no efeito-leitor a significação de que um existe necessariamente em relação ao outro, daí a marca gramatical aditiva - e - que ressoa sentidos em "em relação à violência doméstica $E$ o relacionamento abusivo!". A partir disso, por intermédio dos verbos 'criamos' e 'auxiliamos', no parágrafo final do recorte 2 , as colaboradoras, nas condições dadas e FD's dadas, por meio das Formações Imaginárias (FI) a que tais verbos remontam, se colocam no lugar, pelo mecanismo das relações de poder, de autoridade do conteúdo ali veiculado, porquanto isso seja tanto da ordem da formulação quanto da circulação do discurso que ressoa na página. Retomemos Pêcheux ao dizer que,

[...] em outros termos, o que funciona nos processos discursivos é uma série de formações imaginárias que designam o lugar que A e B se atribuem cada um a si e ao outro, a imagem que fazem de seu próprio lugar e do outro. Se assim ocorre, existem nos mecanismos de qualquer formação social regras de projeção, que estabelecem as relações entre as situações (objetivamente definíveis) e as posições (representações dessas situações) (PÊCHEUX, 1993, p. 82, grifos do autor).

Ou seja, elas têm, por meio da seleção lexical que empreendem nesse trecho, a capacidade de auxiliar mulheres que sofram das violências que ali são problematizadas, demonstrando que não é apenas pelo físico que marcas no sujeito-mulher se fixam. Esse é o efeito de sentido que ressoa pelo nome, descrição e exposição do objetivo desta página.

Constituído pelo acúmulo, o material postado no perfil para auxiliar mulheres a reconhecer as violências que possam sofrer em relacionamentos abusivos fazem parte do discurso digital, ressoando sentidos e inscrevendo-se na memória dessa rede, uma vez que "É só quando há possibilidade de interpretar que a memória metálica se des-organiza na tensão com a memória discursiva, produzindo uma memória digital" (DIAS, 2018, p. 165). Assim, os destaques - recortes 3, 4 e 5 - que trazemos para a reflexão no espaço deste artigo não compreendem todo o arquivo de material que está disponível no perfil em foco. 
Ao todo, sete capturas de tela foram feitas para conseguir registrar todos os storys salvos na atemporalidade do arquivo que faz parte da memória discursivo-digital tanto da página quanto da rede e do discurso em funcionamento dentro e fora do espaço da internet sobre as formas de violência que acometem mulheres. Nos recortes há a didatização para o público poder interpretar e compreender quais são e como se apresentam as outras violências que a nomeação busca contrapor, logo, as que não a forma física de agressão, "As violências física, sexual, emocional e moral [e patrimonial] não ocorrem isoladamente" (SAFFIOTI, 2004, p. 75).

Não empreenderemos uma análise minuciosa de todos os destaques, pois o material é extenso e o foco trata do genérico discursivo no qual o nome produz e desloca a significação. Contudo, é mister ressaltar que todas as postagens estabelecem uma relação necessária e interligada com o interdiscurso e a inscrição na formação discursiva que não a machista/misógina/patriarcal, tais como os exemplos introdutórios expostos neste texto, entendendo que '[...] nos processos discursivos há sempre 'furos', falhas, incompletudes, apagamentos e isto nos serve de indícios/vestígios para compreender os pontos de resistência" (ORLANDI, 2017, p. 213). É no deslize, vestígio da incompletude, que a nomeação da página insurge como resistência e deslocamento de sentidos de uma formulação outrora produzindo efeitos diversos daquilo que as administradoras propõem.

\section{CONSIDERAÇÕES FINAIS}

Procuramos no espaço deste artigo tratar de genéricos discursivos que dizem de uma formação discursiva machista, patriarcal e misógina cristalizada em dizeres acerca da desvalorização do gênero mulher e as violências múltiplas que sofrem em decorrência disso. Para tanto, focar na nomeação de uma página de rede social foi campo profícuo para compreender como os sentidos inscrevem-se em formações discursivas e são terreno para que o interdiscurso funcione e possibilite às significações dos/nos genéricos deslizarem/deslocarem, tal qual é produzido pelo nome e conteúdo veiculado na @ maselenuncamebateu. Também, trazer o espaço do digital como campo a ser explorado enquanto um discurso em funcionamento, formulando e circulando sentidos para/por sujeitos que estão na rede pode ser interpretado como o lugar possível da resistência em amplitude. É pela especificidade desse lugar de efeitos de sentido, o digital, que uma nomeação tal qual a @maselenuncamebateu produz o deslize do efeito metafórico por meio da conjunção adversativa do genérico discursivo e pratica a disseminação (ou viralização?) da/na rede de formulações de dizeres que procuram desestabilizar a violência de gênero como da ordem do naturalizado. Assim, inscrevendo o que outrora era dado a sentidos de invalidação das violências outras na memória discursivo-digital que agora as coloca em debate e reflexões.

\section{REFERÊNCIAS}

BUTLER, Judith P. Problemas de gênero: feminismo e subversão da identidade. Tradução de Renato Aguiar. 2. ed. Rio de Janeiro: Civilização Brasileira, 2008. 
CERVO, Larissa Montagner. Língua, patrimônio nosso. 2012. 198f. Tese (Doutorado em Letras). Universidade Federal de Santa Maria, Santa Maria, RS, 2012.

DIAS, Cristiane. A análise do discurso digital: um campo de questões. REDISCO. Vitória da Conquista, Bahia, v. 10, n. 2, p. 8-20, 2016. ISSN 2316-1213.

DIAS, Cristiane. Análise do discurso digital: sujeito, espaço, memória e arquivo. Campinas, SP: Pontes Editores, 2018.

DIAS, Cristiane. Análise do discurso digital: sobre o arquivo e a constituição do corpus. Estudos Linguísticos, São Paulo, v. 44, n. 3, p. 972-980, set-dez. 2015.

FERREIRA, Maria C. L. O caráter singular da língua na análise de discurso. Organon, v. $17, \quad$ n. $35, \quad 2003$, p. 189-200. Disponível em: https://seer.ufrgs.br/organon/article/view/30023/18619. Acesso em: 15/03/2020.

MARANDIN, Jean-Marie. Sintaxe, discurso: do ponto de vista da análise do discurso. In: Françoise; HAK, Tony. Por uma análise automática do discurso: uma introdução à obra de Michel Pêcheux. Tradutores: Bethania S. Mariani [et al.]. Campinas, SP: Editora da Unicamp, 1993.

MARTINS, Ana Paula. O sujeito "nas ondas" do feminismo e o lugar do corpo na contemporaneidade. Revista café com Sociologia, vol. 4, n. 1, jan-abr 2015. Disponível em:

https://revistacafecomsociologia.com/revista/index.php/revista/article/view/443/pdf_1.

Acesso em: 21/04/2020.

ORLANDI, Eni Puccinelli. Discurso e argumentação: um observatório do político. Fórum Linguístico, Florianópolis, v. 1, n. 1, p. 73-81, jan. 1998. ISSN 1984-8412. Disponível em: <https://periodicos.ufsc.br/index.php/forum/article/view/6915>. Acesso em: 16 jun. 2020.

ORLANDI, Eni P. Discurso e leitura. $7^{\mathrm{a}}$ ed. São Paulo: Cortez, 2007.

ORLANDI, Eni P. Discurso e texto: formulação e circulação de sentidos. $4^{\mathrm{a}}$ ed. Campinas, SP: Pontes Editores, 2012.

ORLANDI, Eni P. Discurso em análise: Sujeito, Sentido e Ideologia. $3^{\text {a }}$ ed. Campinas, SP: Pontes editores, 2017.

PÊCHEUX, Michel. Análise Automática do Discurso (AAD-69). In: GADET, Françoise; HAK, Tony. Por uma análise automática do discurso: uma introdução à obra de Michel Pêcheux. Tradutores: Bethania S. Mariani [et al.]. Campinas, SP: Editora da Unicamp, 1993.

PÊCHEUX, Michel; LÉON, Jacqueline; BONNAFOUS, Simone; MARANDIN, JeanMarie. Apresentação da Análise Automática do Discurso (1982). In: Françoise; HAK, Tony. Por uma análise automática do discurso: uma introdução à obra de Michel Pêcheux. Tradutores: Bethania S. Mariani [et al.]. Campinas, SP: Editora da Unicamp, 1993.

PÊCHEUX, Michel. O Discurso: estrutura ou acontecimento. Tradução: Eni P. Orlandi. $7^{\mathrm{a}}$ ed. Campinas, SP: Pontes Editores, 2015.

PINTO, Célia Regina Jardim. Uma história do feminismo no Brasil. São Paulo: Editora Fundação Perseu Ábramo, 2003.

ROMÃO, Lucília M. S. Nós, desconhecidos, na grande rede. Linguagem em (dis)curso, Tubarão, v. 5, n. 1, p. 71-91, jul/dez. 2004.

SAFFIOTI, Heleieth I. Gênero, patriarcado, violência. $2^{\text {a }}$ reimpressão. São Paulo: Editora Fundação Perseu Abramo, 2011 [2004].

SANTOS, Cecília Macdowell. Da delegacia da mulher à Lei Maria da Penha: lutas feministas e políticas públicas sobre violência contra mulheres no Brasil. Oficina do CES n. 301, Centro de Estudos Sociais, Universidade de Coimbra, março de 2008. Disponível 
em:

https://www.researchgate.net/publication/277237513_Da_Delegacia_da_mulher_a_Lei_ Maria_da_Penha_Lutas_feministas_e_politicas_publicas_sobre_violencia_contra_mulh eres_no_Brasil. Acesso em: 31/01/2020.

SCOTT, Joan. Gênero: uma categoria útil para análise histórica. Educação \& Realidade, Porto Alegre, v. 20, n. 2, p. 71-99, 1995. Disponível em:

$<$ https://seer.ufrgs.br/educacaoerealidade/article/view/71721/40667>. Acesso em: 22/02/2020.

ZOPPI-FONTANA, Mónica. "lugar de fala": enunciação, subjetivação, resistência. Conexão Letras, Porto Alegre, v. 12, n. 18, p. 63-72, 2017. Disponível em: https://seer.ufrgs.br/conexaoletras/article/view/79457. Acesso em: 02/06/2020.

Artigo recebido em: set. de 2020.

Aprovado e revisado em: nov. de 2020.

Publicado em: dez. de 2020.

Para citar este texto:

ALVARES, Jennifer; CERVO, Larissa M. "Mas Ele Nunca Me Bateu": efeitos de sentido em circulação no nome de uma página do Instagram. Entremeios [Revista de Estudos do Discurso, ISSN 2179-3514, on-line, www.entremeios.inf.br], Seção Temática, Programa de Pós-Graduação em Ciências da Linguagem (PPGCL), Universidade do Vale do Sapucaí (UNIVÁS), Pouso Alegre (MG), vol. 22, p. 281-299, jul. - dez. 2020.

DOI: http://dx.doi.org/10.20337/ISSN2179-3514revistaENTREMEIOSvol22pagina281a299 